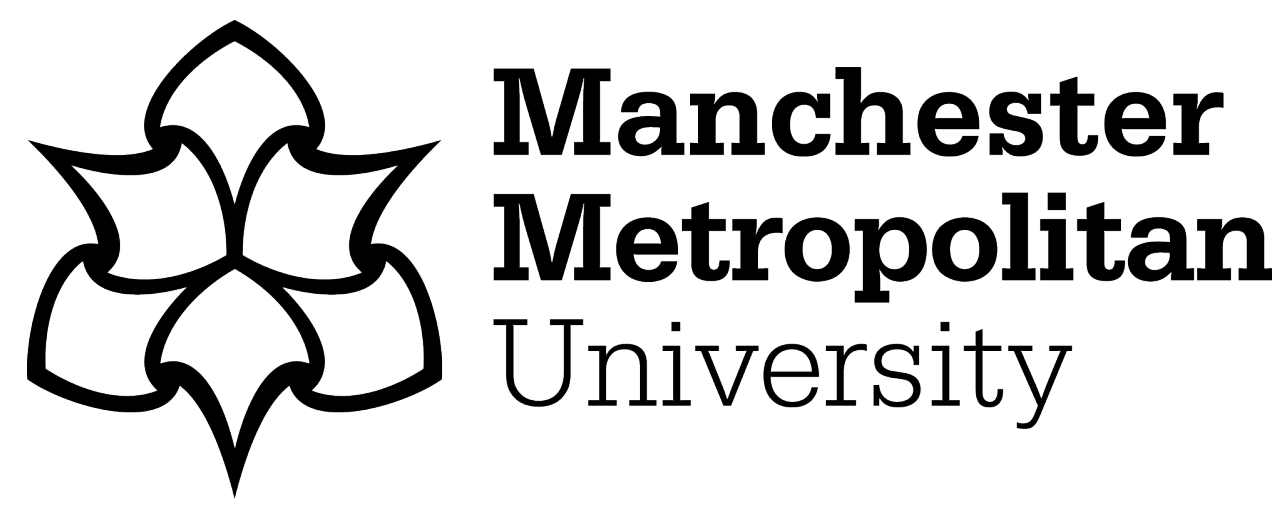

Ratova, Marina, Redfern, James, Verran, J and Kelly, P (2018) Highly efficient photocatalytic bismuth oxide coatings and their antimicrobial properties under visible light irradiation. Applied Catalysis B: Environmental, 239. pp. 223-232. ISSN 0926-3373

Downloaded from: https://e-space.mmu.ac.uk/621154/

Publisher: Elsevier

DOI: https://doi.org/10.1016/j.apcatb.2018.08.020

Usage rights: Creative Commons: Attribution-Noncommercial-No Derivative Works 4.0

Please cite the published version 


\section{Highly efficient photocatalytic bismuth oxide coatings and their antimicrobial properties under visible light irradiation}

Marina Ratova ${ }^{\mathrm{a} *}$, James Redfern ${ }^{\mathrm{b}}$, Joanna Verran ${ }^{\mathrm{b}}$ and Peter J. Kelly ${ }^{\mathrm{a}}$

a Surface Engineering Group, School of Engineering, Manchester Metropolitan University, Manchester, M1 5GD, UK

${ }^{\mathrm{b}}$ School of Healthcare Science, Manchester Metropolitan University, Manchester, M1 5GD, UK

* Corresponding author: M. Ratova, School of Engineering, Manchester Metropolitan University, John Dalton Building, Chester Street, Manchester M1 5GD, UK, tel. +44 161247 4648, e-mail address marina ratova@hotmail.com

\section{Abstract}

The aim of the present paper is to assess the antimicrobial activity of novel narrow band gap semiconductor photocatalysts under visible light irradiation, compared to titanium dioxide, which is the conventionally used photocatalytic material. Bismuth oxide, bismuth tungstate and titanium dioxide coatings were prepared using pulsed DC reactive magnetron sputter deposition onto batches of $2 \mathrm{~mm}$ spherical glass beads that were agitated during the deposition process to ensure uniform coverage. Additional coatings were deposited onto flat glass substrates for specific analytical techniques. Following deposition, the coatings were annealed in air at $673 \mathrm{~K}$ for $30 \mathrm{~min}$ to enable crystal structure development. Annealed coatings were analysed with SEM, EDX, XRD, XPS, AFM, UVvisible spectroscopy and water contact angle measurements. The photocatalytic properties of the coatings were initially assessed via a Rhodamine B dye degradation test under visible light irradiation. Antimicrobial efficiency of the coatings was tested via inactivation of $E$. coli; additionally, bacterial adhesion experiments were performed for all types of the studied coatings. It was found that the performance of bismuth oxide for both dye degradation and bacterial inactivation experiments under visible light was superior to that observed for either bismuth tungstate or titanium dioxide. Moreover, bismuth oxide coatings (and to a lesser extent - bismuth tungstate), due to its hydrophobic nature was able to inhibit bacterial adhesion to the surface.

Keywords: bismuth oxide; bismuth tungstate; titanium dioxide; photocatalysis; visible light; antimicrobial.

\section{Introduction}

As the levels of industrialization and urbanization in the modern world increases, so will the amount of waste, with increasing potential to contaminate water, air and soil. Consequently, there is an urgent requirement for reliable and efficient methods to treat persistent organic pollutants [1] as well as microbial contamination [2, 3]. Over the past few decades, photocatalysis has gained popularity as a safe, cheap and sustainable method of air and water decontamination. Of the practical applications of photocatalysis, water treatment is of particular importance, as it provides a relatively simple, yet efficient technique of mineralizing organic contaminants to carbon dioxide and water without the production of secondary pollutants.

Since discovery of its photocatalytic properties by Fujishima and co-workers in 1969 [4], titanium dioxide $\left(\mathrm{TiO}_{2}\right)$ is the most studied and applied photocatalytic material, with many reviews describing the utilization of titania for decontamination, depollution and disinfection processes [5]. Owing to its 
high chemical stability, low cost and non-toxicity, titanium dioxide is generally considered to be the most efficient photocatalytic material. The case for $\mathrm{TiO}_{2}$ is further supported by the wealth of literature describing the ability to kill microorganisms via radical oxygen species generation [6]. Many of these studies selected Escherichia coli (E. coli) as their model microorganism for standard test methods to assess photocatalytic materials [7] and as an indicator in water pollution [8]. Moreover, as a photocatalytic material, titanium dioxide is frequently mentioned as being more effective than other antibacterial agents, due to its long-term antimicrobial effect and inertness to the surfaces it is in contact with [9]. However, there are a number of drawbacks that limit its practical application. Firstly, the relatively low band gap of titanium dioxide $(3.2 \mathrm{eV}$ for the anatase phase, typically reported as the most photocatalytically active phase of $\mathrm{TiO}_{2}$ ), means that it can only be activated by UV light with a wavelength below $387.5 \mathrm{eV}$. Therefore, to utilize natural sunlight for photoactivation of titanium dioxide, structural modifications are required [10], such as doping [11$14]$, coupling with a narrow-band gap semiconductor $[15,16]$ or sensitization [17]. Secondly, fast rates of recombination of photogenerated charge carriers mean that the photonic efficiency of titanium dioxide is rather low. With these known limitations of titanium dioxide, it is not surprising that there is a growing interest in the development of photocatalytic materials that are directly visible light responsive. Of the variety of narrow-band gap semiconducting materials, bismuth oxide / complex oxides are frequently reported as efficient visible light activated photocatalysts [18]. Of the bismuth complex oxides, high rates of visible light photocatalytic activity have been reported for bismuth vanadate [19-21], titanate [22], tungstate [23] and molybdate [24, 25]. Bismuth tungstate is one of the most studied bismuth metallates, offering such attractive properties as high visible light / solar photocatalytic activity, relatively low band gap and high stability [26]. Overall, bismuth tungstate has been shown to be capable of degrading a wide range of pollutants, including inorganic dyes [18, 27, 28], volatile organic compounds [29], nitric oxides [30] and pharmaceuticals [31]. Furthermore, bismuth oxide and bismuth tungstate have recently been reported as efficient photocatalysts for water treatment processes [18, 32]. However, for efficient water treatment processes, disinfection is as important as decontamination, and the disinfecting properties of photocatalytic bismuth-based oxides are considerably less studied to date - few reports refer to photocatalytic bismuth (complex) oxides as antimicrobial materials [33-35]. Bismuth oxide itself is considerably less studied. Though it is a low band gap semiconductor, very few reports to date refer to it as a photocatalytic material $[18,36,37]$. None of the reports, however, discuss photocatalytic disinfection using bismuth oxide.

Though the powder-form photocatalytic material, titanium dioxide Degussa P25, still remains the most used photocatalytic material in the world, it is a well-known fact that the use of powdered photocatalysts for water disinfection / depollution processes require the additional step of postprocess separation. Therefore, immobilization of the photocatalyst onto a solid substrate is preferred for ease of recovery; this can be done with various chemical or physical deposition techniques. Magnetron sputtering (MS), though previously considered as a "line of sight process" has recently been proven by the authors to be a promising technique for coating powdered or particulate substrates $[15,16,18]$. Moreover, it offers such advantages as ease of control, high film uniformity, and, most importantly, excellent scalability [38]. The latter one makes MS the process of choice for various industrial coating processes, including for example, the production of self-cleaning architectural glazing, which relies on a photocatalytic coating for its functionality [39]. 
Development of a photocatalytic material that is visible-light activated and demonstrates the ability to not only breakdown organic pollutants but also kill microorganisms may hold numerous benefits for water treatment processes. Therefore, the present study describes the antimicrobial properties of photocatalytic coatings deposited onto $2 \mathrm{~mm}$ diameter spherical glass beads via reactive magnetron sputtering. The antimicrobial efficiency of the coatings was evaluated via their ability to inactivate $E$. coli bacteria under visible light irradiation. The performance of the most frequently used photocatalytic material - titanium dioxide - was compared with that of bismuth tungstate coatings (one of the most often referred to efficient visible light photocatalytic materials), and to bismuth oxide. To the best of the authors' knowledge, antimicrobial properties of photocatalytic bismuth oxide coatings have not been reported elsewhere to date.

\section{Experimental}

\subsection{Deposition of the coatings}

All of the studied coatings were deposited in a single-stage process in a sputtering system comprising of two $300 \times 100 \mathrm{~mm}$ closed field unbalanced type II planar magnetrons installed through the chamber roof in a co-planar sputter down configuration, facing the substrate holder - a detailed description and schematic of the rig are available elsewhere [15]. An oscillator bowl combining vertical oscillations with lateral twisting movements was used as the substrate holder. The design of the oscillator is described in detail elsewhere; [16] it is designed to enable the magnetron sputter deposition of uniform coatings onto particulate substrates as they traverse under both magnetrons. A $15 \mathrm{~g}$ charge of $2 \mathrm{~mm}$ round glass balls (purchased from Sigma Aldrich) was used as the substrate in this instance. The glass beads were ultrasonically pre-cleaned in propanol prior to deposition (all reagents were purchased from Sigma Aldrich, unless stated otherwise). For the deposition of bismuth tungsten oxide coatings, a bismuth target was fitted to one of the magnetrons, while a tungsten target was fitted to the other (both targets were 99.5\% pure and bonded to copper backing plates). For the deposition of bismuth oxide coatings, no power was applied to the tungsten target. For the deposition of titanium dioxide coatings, titanium targets ( $99.5 \%$ pure) were fitted to both magnetrons. The targets were sputtered in reactive mode in argon / oxygen atmospheres at a partial pressure of $0.4 \mathrm{~Pa}$. The flows of argon and oxygen were controlled via mass-flow controllers; $10 \mathrm{sccm}$ of $\mathrm{Ar}$ and $20 \mathrm{sccm}$ of $\mathrm{O}_{2}$ were used for all deposition runs. The magnetrons were operated in pulsed $\mathrm{DC}(\mathrm{pDC})$ mode using a dual channel Advanced Energy Pinnacle Plus power supply, where a pulse frequency of $100 \mathrm{kHz}$ and duty of $50 \%$ (synchronous mode) were used for the deposition of all the studied coatings. A summary of the deposition conditions is given in the Table 1.

Table 1. Summary of deposition conditions used for production of photocatalytic coatings

\begin{tabular}{|l|l|l|l|}
\hline & Bismuth oxide & $\begin{array}{l}\text { Bismuth tungsten } \\
\text { oxide }\end{array}$ & Titanium dioxide \\
\hline Target material & $\mathrm{Bi}(\mathrm{x} 1)$ & $\mathrm{Bi}$ and $\mathrm{W}$ & $\mathrm{Ti}(\times 2)$ \\
\hline Substrate & $\begin{array}{l}15 \mathrm{~g} \text { of } 2 \mathrm{~mm} \text { glass } \\
\text { beads }\end{array}$ & $\begin{array}{l}15 \mathrm{~g} \text { of } 2 \mathrm{~mm} \text { glass } \\
\text { beads }\end{array}$ & $\begin{array}{l}15 \mathrm{~g} \text { of } 2 \mathrm{~mm} \text { glass } \\
\text { beads }\end{array}$ \\
\hline Ar flow & $10 \mathrm{sccm}$ & $10 \mathrm{sccm}$ & $10 \mathrm{sccm}$ \\
\hline $\mathrm{O}_{2}$ flow & $20 \mathrm{sccm}$ & $20 \mathrm{sccm}$ & $20 \mathrm{sccm}$ \\
\hline
\end{tabular}




\begin{tabular}{|l|l|l|l|}
\hline $\begin{array}{l}\text { Time-averaged power } \\
\text { applied to } \\
\text { magnetrons, W }\end{array}$ & 600 & $300(\mathrm{Bi})$ and $300(\mathrm{~W})$ & $300(\times 2)$ \\
\hline Target current, A & 3.20 & $2.20(\mathrm{Bi})$ and $1.30(\mathrm{~W})$ & $2.60(\times 2)$ \\
\hline Target voltage, $\mathrm{V}$ & -190 & $-140(\mathrm{Bi})$ and $-230(\mathrm{~W})$ & $-230(\times 2)$ \\
\hline
\end{tabular}

Additionally, coatings of each composition were also deposited onto soda-lime glass flat substrates to enable determination of the photoinduced wettability of the films; the deposition times were adjusted to produce the same thickness of coatings as on the glass beads described above.

All the studied coatings were post-deposition annealed at $673 \mathrm{~K}$ for $30 \mathrm{~min}$ in air and then allowed to cool in air gradually (5-6 h) to avoid the formation of the thermal stresses in the coatings.

\subsection{Characterisation of the coatings}

The crystallography of the coatings was studied with X-ray diffraction (XRD) (Panalytical Xpert powder with CuKa1 radiation at $0.154 \mathrm{~nm}$ in grazing incidence mode at $3^{\circ}$ over a scan range from $20^{\circ}$ to $70^{\circ} 2 \theta$; the accelerating voltage and applied current were $40 \mathrm{kV}$ and $30 \mathrm{~mA}$, respectively). The coating thicknesses and elemental composition were studied with SEM / EDX (EDAX Trident, Edax Co. installed on a Zeiss Supra 40 VP-FEG-SEM). The surface area and surface roughness of the coatings were determined with atomic force microscopy (AFM) (Veeco NanoScope IV MultiMode AFM in contact mode, scan area of $30 \mu \mathrm{m}$, the surface parameters were determined as mean values of 5 scans). The oxidation state information was obtained by X-ray photoelectron spectroscopy (XPS) (AMICUS photoelectron spectrometer equipped with a MgKa X-ray as a primary excitation source, and using Ag $3 \mathrm{~d}$ as a reference binding energy at $368.2 \mathrm{eV}$ ). Determination of the band gaps of the coatings was performed using the Tauc plot method, described in detail elsewhere [40], by plotting $(\alpha h v)^{1 / 2}$ as a function of hv and extrapolating the linear region to the abscissa (where $\alpha$ is the absorbance coefficient, $h$ is Plank's constant, $v$ is the frequency of vibration). The photoinduced wettability of the coatings was assessed at ambient temperature using identical coatings deposited onto the flat substrates (described in the Deposition of coatings section), through analysing the changes of static water droplet contact angle (WCA) with a Theta Lite optical tensiometer (Biolin Scientific), while irradiating with a visible light source (details of the light source are given in the Photocatalytic activity assessment section).

\subsection{Photocatalytic activity assessment}

The initial assessment of photocatalytic activity was made using a Rhodamine $B(\mathrm{RhB})$ degradation test. Rhodamine $\mathrm{B}$ is an organic dye, one of the most frequently used model compounds for the assessment of the photocatalytic activity, with a chemical formula $\mathrm{C}_{28} \mathrm{H}_{31} \mathrm{ClN}_{2} \mathrm{O}_{3}$. Aqueous solutions of RhB have an intense colour and an absorbance peak at a wavelength of $554 \mathrm{~nm}$; the rate at which the peak height decayed during the test was used as a measure of the degradation rate of the dye in contact with the photocatalyst. The studies of photocatalytic activity were performed using a visible light source with a $60 \mathrm{~W}$ daylight bulb. The emission spectrum of the irradiance source is given in Figure 1; the integrated irradiance value in the wavelength range $400-800 \mathrm{~nm}$ was $190 \mathrm{~W} / \mathrm{m}^{2}$. 


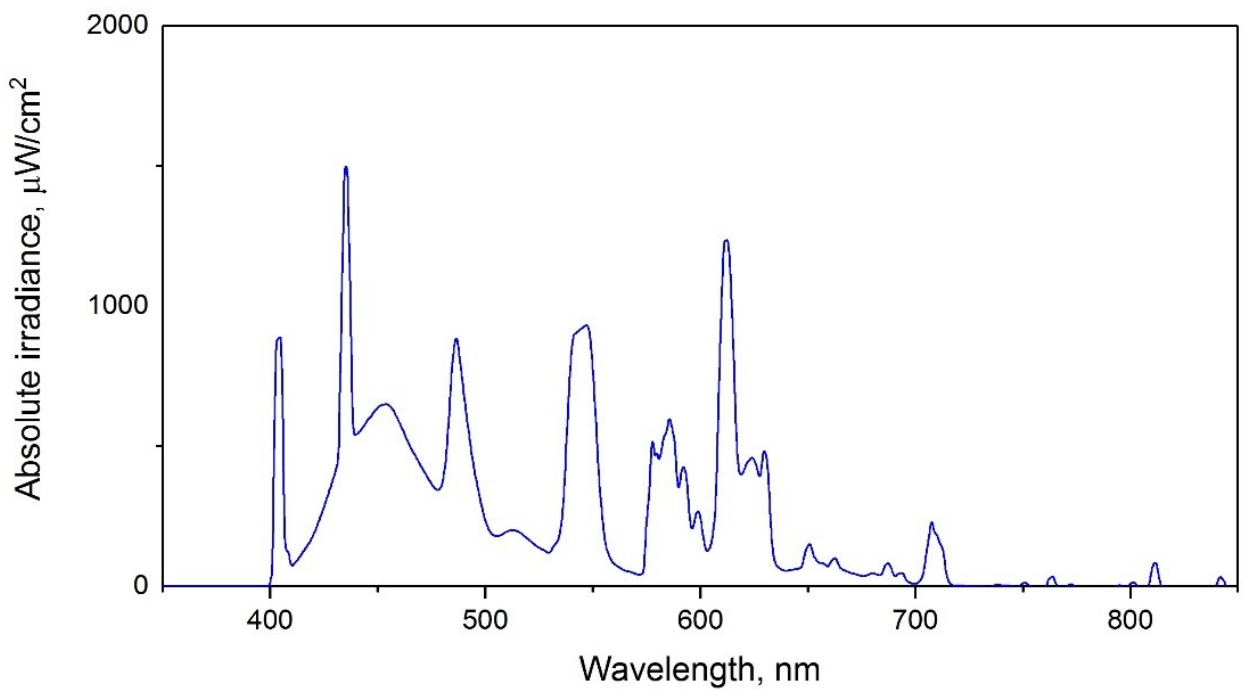

Figure 1. Emission spectrum of the light source used for photoactivation of the surfaces

The concentration of the testing solution here was $20 \mu \mathrm{mol} / \mathrm{l}$. A $4 \mathrm{~g}$ load of the coated beads was used for each experiment. An additionally series of reference tests was also carried out, including testing the uncoated beads in dark and light conditions; tests of the coated beads in the dark; and dye solution photolysis rate tests under the irradiation source used with no photocatalyst present. Prior to the measurement of the Rhodamine B dye absorbance decay, all samples were immersed into a conditioning solution of the dye (the same concentration as the testing solution) and kept in the dark at room temperature for $1 \mathrm{~h}$ with continuous magnetic stirring to reach the adsorptiondesorption equilibrium. After being withdrawn from the conditioning solution, the coated beads were placed into $40 \mathrm{~mL}$ of testing solution of RhB with continuous magnetic stirring, while being irradiated with the visible light source. The total absorbance decay measurement time was $1 \mathrm{~h}$ for all testing runs, including the reference ones.

\subsection{Antimicrobial activity assessment}

\subsubsection{Maintenance and standardisation of microorganisms}

Escherichia coli (E. coli) NCTC 9001 was stored in glycerol stock at $-80{ }^{\circ} \mathrm{C}$. For experimental work, the microorganism was subcultured from the stock onto Luria-Bertani (LB) agar (BD, Sparks, MD), and stored in a fridge $\left(4^{\circ} \mathrm{C}\right)$, for no more than four weeks. For testing antimicrobial potential, 2-4 colonies of $E$. coli were inoculated into $100 \mathrm{~mL}$ of Tryptone Soya broth (TSB, Oxoid, Basingstoke) and grown for $22 \pm 1$ hours at $37^{\circ} \mathrm{C}$ with agitation ( $180 \mathrm{rpm}$ ). Cells were harvested by centrifugation $(3,600 \mathrm{rpm}, 10 \mathrm{~min})$ and resuspended in sterile distilled water to an optical density of 0.25 at $540 \mathrm{~nm}$ (Jenway 6305 Spectrophotometer, UK) resulting in a "standardised cell suspension" of $1.25 \pm$ $0.17 \times 10^{8} \mathrm{CFU} \mathrm{mL} \mathrm{L}^{-1}$.

\subsubsection{Testing for antimicrobial activity}

Uncoated glass beads and beads coated with either bismuth oxide, bismuth tungstate or titanium dioxide were weighed into individual $1 \mathrm{~g} \pm 0.1 \mathrm{~g}$ batches and autoclaved for 15 minutes at $121^{\circ} \mathrm{C}$. Each $1 \mathrm{~g}$ of beads was placed into an individual well of a 12-well multidish (Thermo Fisher Scientific, Roskilde). Each well was then inoculated with $1 \mathrm{~mL}$ of standardised cell suspension (as described 
above). Each type of bead was tested in three wells, and each set of three was tested in either a dark environment (wrapped in foil) or irradiated with the visible light source described earlier in section 2.3. Samples were kept in a plastic box $(20 \mathrm{~cm} \times 20 \mathrm{~cm} \times 10 \mathrm{~cm}$ with a clear lid to allow irradiation) containing moist paper-towels, ensuring the container would remain humid. The box containing multidishes was then placed on an orbital shaker $(100 \mathrm{rpm})$ for the duration of the experiment. $25 \mu \mathrm{l}$ samples were taken from each well at given time-points ( $6 \mathrm{~h}, 24 \mathrm{~h}, 48 \mathrm{~h}$ and $72 \mathrm{~h}$ ) and serially diluted ten-fold in sterile distilled water to a dilution of $10^{-7} .100 \mu \mathrm{l}$ of each dilution was spread on to nutrient agar (Oxoid, Basingstoke) in duplicate and incubated overnight at $37^{\circ} \mathrm{C}$. Colonies were counted and colony forming units (CFU) per $\mathrm{mL}^{-1}$ of original suspension were calculated. The experiment as a whole was repeated once.

\subsubsection{Counting of microorganisms adhered to coated beads}

Beads were assessed for adhered cells to ensure any reduction in CFU mL ${ }^{-1}$ observed in liquid suspension described above was due to the death of cells and not adhesion onto the bead. Ten beads (approximately $0.7 \mathrm{~g}$ ) of each type were washed in sterile distilled water to remove any nonadhered cells. The beads were transferred into $1 \mathrm{~mL}^{-1}$ of sterile water and vortex mixed for 60 seconds, followed by ten minutes in a sonicating water bath and a further 60 seconds vortex mix. The resultant $100 \mu \mathrm{L}$ of each suspension was serially diluted to $10^{-7} .100 \mu \mathrm{L}$ of each dilution was spread on to Nutrient Agar (Oxoid, Basingstoke) in duplicate and incubated overnight at $37^{\circ} \mathrm{C}$. Microbial growth was counted and calculated into colony forming units (CFU) per $\mathrm{mL}$. Within each experiment, each of the four types of coated bead were tested three times, and the experiment as a whole was repeated once.

\subsubsection{Comparison of adhered bacteria to coated glass surfaces}

In order to quantify the ability for cells to adhere to each surface type, a comparison of adhesion was performed on flat glass-coated surfaces. Plain glass slides or glass slides coated with either bismuth oxide, bismuth tungstate or titanium dioxide were autoclaved for 15 minutes at $121^{\circ} \mathrm{C}$ to ensure sterility. Slides were then placed coating-side up inside a polystyrene box $(80 \mathrm{~mm} \times 123 \mathrm{~mm} \times$ $7 \mathrm{~mm}$ ) and submerged in $35 \mathrm{~mL}$ of standardised E. coli culture (as described above) for two hours (providing an approximate depth of suspension above the slide of $5 \mathrm{~mm}$ ). Each slide was removed and washed gently with $25 \mathrm{~mL}$ of sterile distilled water (using an auto-pipette) to remove any nonadhered cells. Slides were then stained with acridine orange (Sigma, Dorset, UK) $(0.03 \%$ in $2 \%$ glacial acetic acid) (VWR, Lutterworth), and the surfaces were rinsed and dried before examination with confocal scanning laser microscopy (CSLM - TCS SPE1000, Leica) with x40 water-dipping lens. Twenty random fields of each of three replicate surfaces were examined. The percentage area of each field covered by cells were calculated using ImageJ Fiji [41].

\subsubsection{Removal and killing of adhered bacteria from stainless steel using coated glass beads.}

The beads were assessed for the removal and killing of $E$. coli cells adhered on stainless steel, as an example of a potential application. Eight stainless steel 304 coupons $(1 \times 1 \mathrm{~cm})$ (Outokumpu, Sheffield, UK) were inoculated with $5 \mathrm{~mL}$ of standardised cell suspension as described earlier in section 2.4.4 and left stationary at room temperature for 3 hours to allow cells to adhere to the surface. Each coupon was removed and washed gently with $25 \mathrm{~mL}$ of sterile distilled water (using an auto-pipette) to remove any non-adhered cells. Two coupons were set aside as untested controls for 
qualitative analysis of adhered cells using CSLM (described below). The remaining six coupons were then placed in an individual well of a 12-well multidish and submerged in $2 \mathrm{~mL}$ sterile distilled water. Either $1 \mathrm{~g}$ of uncoated glass beads, $1 \mathrm{~g}$ of bismuth oxide-coated beads or no beads were added to two wells containing a coupon. The multidish was then placed under constant irradiation (as described in section 2.4.2), placed on an orbital shaker ( $100 \mathrm{rpm}$ ) and left for 72 hours. Following this, $100 \mu$ aliquots were taken from each well and diluted using a 10 -fold serial dilution to $10^{-8} .100$ $\mu l$ of each dilution was spread on to Nutrient Agar and incubated overnight. All six coupons were gently rinsed with $5 \mathrm{~mL}$ of sterile distilled water using an autopipette and stained with $100 \mu \mathrm{l}$ LIVE/DEAD BacLight ${ }^{\text {TM }}$ (Fisher Scientific) at a ratio of 1:1. Qualitative examination was carried out using a Leica TCS SPE 1000 CLSM, x40 water dipping lens and the Leica Application Suite X software package.

\section{Results}

\subsection{Coatings overview}

As the results presented are part of an on-going project, and structural / morphological properties of the coatings have already been described elsewhere in detail [18], the present work will only focus on the properties that are important in the context of the antimicrobial activity tests performed. The main properties of the studied coatings deposited onto $2 \mathrm{~mm}$ glass beads and annealed at $673 \mathrm{~K}$ are summarised in Table 2.

In terms of their visual appearance, all three coatings were visibly transparent and uniformly distributed on the surface of the glass beads, with no apparent cracks or stresses. The colour of the coatings varied from intense yellow (bismuth oxide) and pale yellow (bismuth tungstate) to colourless (titanium dioxide).

The elemental composition of the coatings was obtained with EDX and verified on five coated beads on three points for each sample. The variation of the values was no greater than $5 \%$, confirming the uniformity of the coatings deposited with the use of the oscillating substrate holder. The mean value of five measurements is given for each coating in Table 2. As can be seen from the results, the compositions of the bismuth oxide and the titanium oxide coatings were close to stoichiometric $\mathrm{Bi}_{2} \mathrm{O}_{3}$ and $\mathrm{TiO}_{2}$, respectively. The composition of the bismuth tungstate coating was close to $\mathrm{Bi}_{2} \mathrm{WO}_{6}$. The ratio of bismuth / tungsten in this coating was close to 2/1 (reportedly, the most beneficial composition for the photocatalytic properties $[18,23])$.

The thickness of the coatings deposited onto the glass beads was estimated from cross-sectional SEM micrographs and the values are given in the Table 2; selected cross-sectional and top view SEM micrographs are given in the Figure S1. It is evident that, of the three coatings studied, bismuth oxide had the highest thickness, confirming that, since all the coatings were deposited at the same 
total power, the sputtering yield of bismuth is considerably higher than that of titanium or tungsten [42], resulting in a higher apparent deposition rate.

Table 2. Overview of compositional, surface, phase, optical and photocatalytic properties of the coatings deposited onto $2 \mathrm{~mm}$ glass beads and annealed at $673 \mathrm{~K}$.

\begin{tabular}{|l|l|l|l|l|l|l|l|l|}
\hline Sample & $\begin{array}{l}\text { Compositi } \\
\text { on, at.\% }\end{array}$ & $\begin{array}{l}\text { Coating } \\
\text { thicknes } \\
\text { s, nm }\end{array}$ & $\begin{array}{l}\text { Main } \\
\text { crystal } \\
\text { phase }\end{array}$ & $\begin{array}{l}\text { Surface } \\
\text { roughne } \\
\text { ss, nm }\end{array}$ & $\begin{array}{l}\text { Surfac } \\
\text { e } \\
\text { area, } \\
\mu m^{2}\end{array}$ & $\begin{array}{l}\text { Ban } \\
\mathrm{d} \\
\text { gap, } \\
\mathrm{eV}\end{array}$ & $\begin{array}{l}\text { Average } \\
\text { Transmittan } \\
\text { ce Value } \\
\text { in the } \\
\text { Visible Part } \\
\text { of the } \\
\text { Spectrum } \\
(\%)\end{array}$ & $\begin{array}{l}\text { Rhodamin } \\
\text { e B } \\
\text { degradati } \\
\text { on } \\
\text { constant, } \\
\mathrm{k}_{\mathrm{a}} \times 10^{-5}, \mathrm{~s}^{-1}\end{array}$ \\
\hline $\begin{array}{l}\text { Bismut } \\
\text { h oxide }\end{array}$ & $\begin{array}{l}44(\mathrm{Bi}) / 56 \\
(\mathrm{O})\end{array}$ & 340 & $\begin{array}{l}\text { Bismut } \\
\text { h oxide }\end{array}$ & 8.3 & 904 & 2.40 & 67.82 & 3.75 \\
\hline $\begin{array}{l}\text { Bismut } \\
\mathrm{h} \\
\text { tungsta } \\
\text { te }\end{array}$ & $\begin{array}{l}27(\mathrm{Bi}) / 11 \\
(\mathrm{~W}) / 62 \\
(\mathrm{O})\end{array}$ & 210 & $\begin{array}{l}\text { Russelit } \\
\mathrm{e} \\
\text { bismuth } \\
\text { tungsta } \\
\text { te }\end{array}$ & 6.6 & 902 & 2.57 & 70.82 & 3.09 \\
\hline $\begin{array}{l}\text { Titaniu } \\
\mathrm{m} \\
\text { dioxide }\end{array}$ & $\begin{array}{l}34(\mathrm{Ti}) / 66 \\
(\mathrm{O})\end{array}$ & 90 & $\begin{array}{l}\text { Anatase } \\
\text { titania }\end{array}$ & 4.8 & 900 & 3.21 & 80.40 & 0.47 \\
\hline
\end{tabular}

\subsection{Coatings characterization}

While all as-deposited coatings had an amorphous microstructure (patterns not shown here), annealing for $30 \mathrm{~min}$ at $673 \mathrm{~K}$ resulted in the development of crystallinity. The XRD patterns of the studied coatings deposited onto glass beads after thermal treatment are given in Figure 2. According to the data from the crystallographic database, the obtained XRD patterns correspond to bismuth oxide (JCPDS 96-901-2328), the russelite phase of bismuth tungstate (JCPDS 96-101-1216) and the anatase phase of titanium dioxide (JCPDS 96-900-8215), respectively. While anatase phase is reportedly the most photoactive phase of titanium dioxide, the information on the photocatalytic 
activity of various phases of bismuth tungstate and bismuth oxide varies significantly, depending on the preparation method and stoichiometry of the materials.

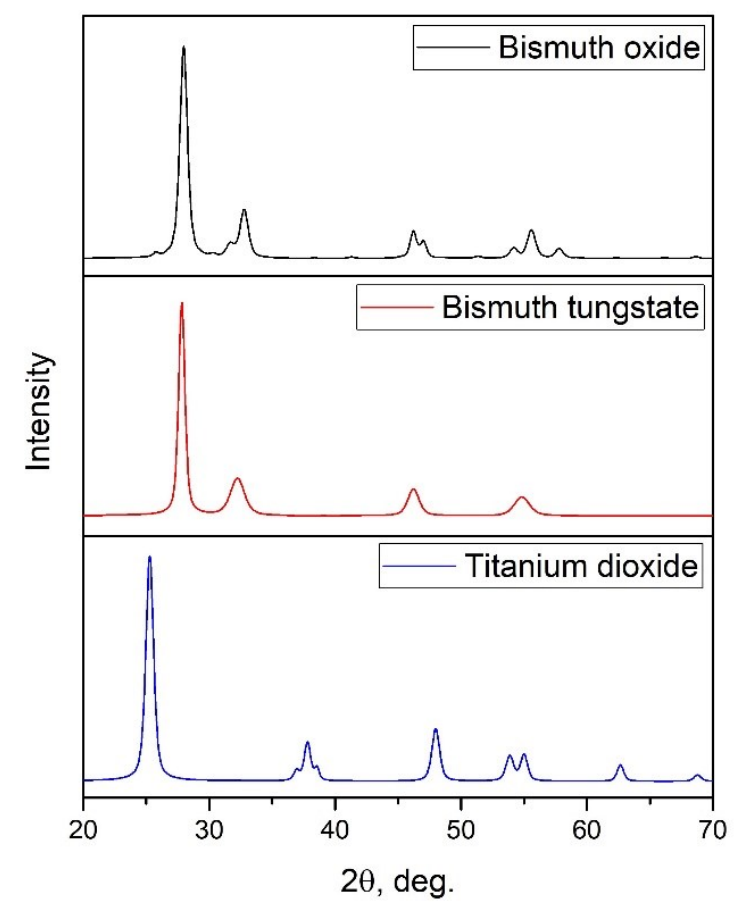

Figure 2. XRD patterns of coatings deposited onto 2-mm glass beads and annealed at $673 \mathrm{~K}$

Values of the surface area $\left(S_{a}\right)$ and the surface roughness $\left(R_{a}\right)$ were obtained with the AFM (given in the Table 2, examples of the AFM images of the studied coatings are given in the Figure S2); it is evident that all three types of coated beads studied had relatively smooth surfaces, with the variation of the surface area between all three types of samples being lower than $1 \%$. As higher values of the surface area result in a higher contact area with the pollutant, absence of a large variation in the surface area values of the studied coatings enables direct comparison of the photocatalytic performance of the beads, rather than normalising it per unit of surface area.

XPS was used for determination of the chemical states of the elements; the XPS spectra are given in Figure 3. Gaussian functions were used for deconvolution of the individual peaks. The carbon (C 1s) peak at $284.8 \mathrm{eV}$ was observed on the survey spectra of all samples (not shown); the presence of this peak is typically explained by adventitious carbon. The binding energies were referenced to the $C 1 \mathrm{~s}$ peak at $284.8 \mathrm{eV}$ of the surface adventitious carbon. The high-resolution spectrum of $\mathrm{Bi} 4 \mathrm{f}$ of the bismuth oxide sample is given in Figures 3a; the binding energies of the $\mathrm{Bi} 4 \mathrm{f}$ of the bismuth oxide sample appeared at ca. $158.3 \mathrm{eV}$ and $163.6 \mathrm{eV}$. The high-resolution spectra of Bi $4 \mathrm{f}$ and $\mathrm{W} 4 \mathrm{f}$ of the bismuth tungstate samples are given in Figures $3 c$ and $3 d$, respectively. Similarly to bismuth oxide, the $\mathrm{Bi} 4 \mathrm{f}$ spectrum has two peaks at $158.3 \mathrm{eV}$ and $163.6 \mathrm{eV}$, while $\mathrm{W} 4 \mathrm{f}$ peaks were found at ca. 34.8 and $37.0 \mathrm{eV}$. On the high-resolution spectrum of the Ti $2 \mathrm{p}$ titanium dioxide sample (Figure $3 \mathrm{f}$ ), the peak positioned at ca. $458.3 \mathrm{eV}$ corresponds to $\mathrm{Ti} 2 \mathrm{p}_{3 / 2}$, while the peak at ca. $464.1 \mathrm{eV}$ can be assigned to Ti $2 p_{1 / 2}$. The high-resolution spectra of $\mathrm{O} 1 \mathrm{~s}$ for the bismuth oxide, bismuth tungstate and titanium dioxide samples are shown in Figures $3 \mathrm{~b}, 3 \mathrm{e}$ and $3 \mathrm{~g}$, respectively. It can be seen that in all cases, the peak can be deconvoluted into two, where the $O$ 1s binding energy at $529.5 \mathrm{eV}$ can be attributed to the lattice oxygen, while the $\mathrm{O} 1 \mathrm{~s}$ peak $531.3 \mathrm{eV}$ is typically attributed to the organic C$O$ bonds. It should be noted that the positions of all observed peaks were in good agreement with 
the literature information $[18,30,43]$. Additionally, the elemental ratios estimated with the XPS were consistent with the EDX data, allowing the suggestion that the distribution of the elements was consistent through the thickness of the coatings.
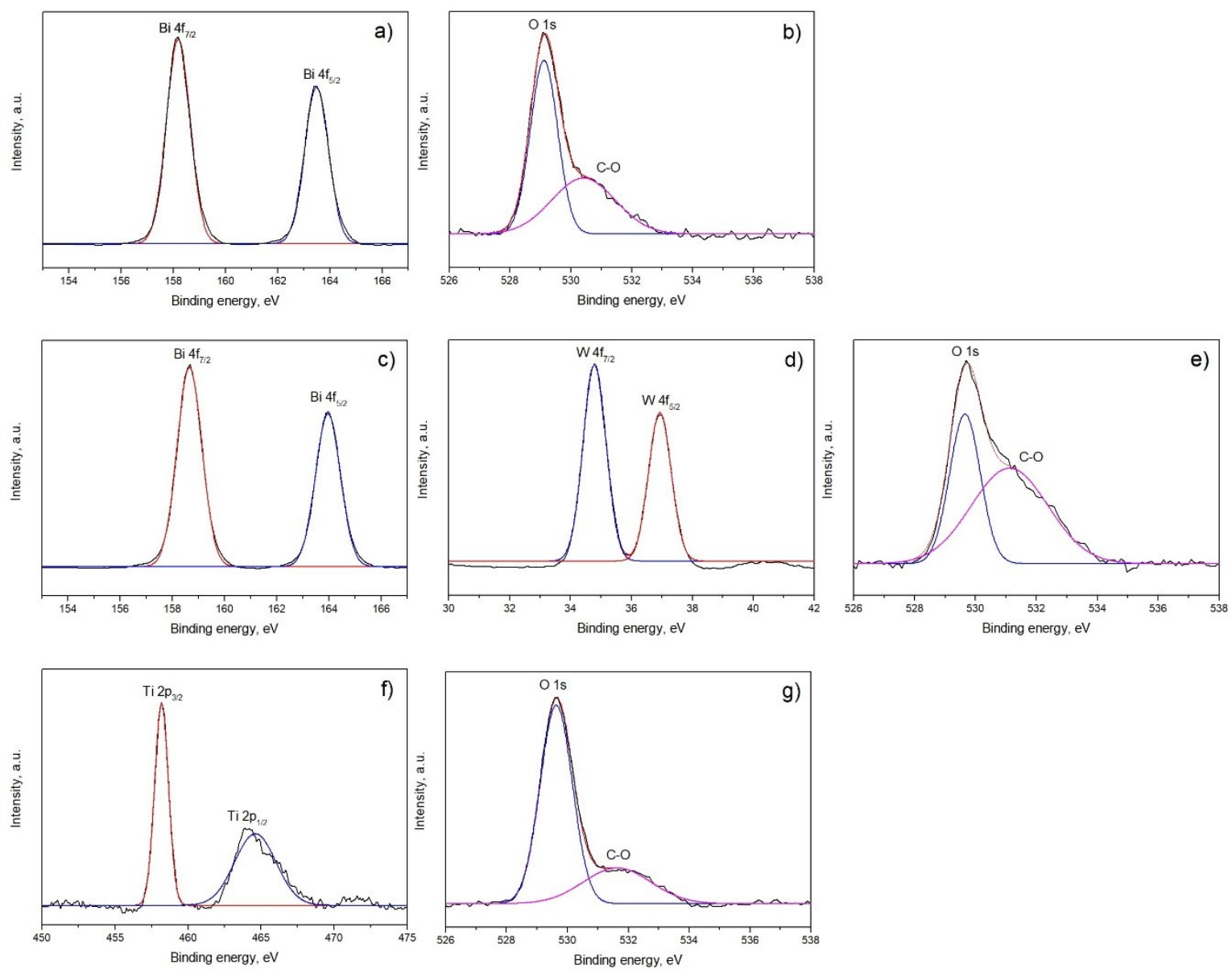

Figure 3. XPS spectra of $2 \mathrm{~mm}$-coated glass beads annealed at 673K: bismuth oxide a) Bi $4 f$ spectrum, b) $O$ 1s spectrum; bismuth tungstate c) Bi $4 f$ spectrum, d) W $4 f$ spectrum, e) $O$ 1s spectrum; titanium dioxide f) Ti $2 p$ spectrum, $g$ ) $O 1 \mathrm{~s}$ spectrum

Optical band gap values of the deposited coatings were determined using UV-vis spectroscopy and the Tauc plot method. The obtained values are given in Table 2. The plots of the band gap calculations are depicted in the Figure S3. As given in this table, values of $2.40,2.57$ and $3.21 \mathrm{eV}$ were obtained for bismuth oxide, bismuth tungstate and titanium dioxide, respectively. According to these results, it can be assumed that bismuth-based coatings are likely to be photoactivated with the chosen light source, while the energy of its light is below the value required for photoactivation of titanium dioxide.

\subsection{Photocatalytic activity assessment}

The photocatalytic activity of the samples was evaluated by degradation of Rhodamine B dye under visible light irradiation. Rhodamine $B$ is an azo-dye and a typical wastewater pollutant from the textile industry; moreover, it is one of the most common model pollutants used for testing bismuth complex oxide photocatalytic properties $[28,32,44]$. The plots of RhB degradation kinetics during each $1 \mathrm{~h}$ experiment are presented in Figure 4 , and the calculated pseudo-first order reaction 
constants, $k_{a}$, are given in Table 2. The blank control test (with no sample present) demonstrated that degradation of $\mathrm{RhB}$ due to photolysis alone occurred at very slow rate (less than $4 \%$ during $1 \mathrm{~h}$ irradiation time). The series of dark reference tests (each sample was tested in the dark) revealed that the RhB absorbance peak reduction was no more than $1 \%$, therefore these data were neglected in further calculations of the reaction constants. The photocatalytic efficiency of the three samples tested was distinctively different; the highest rate of $\mathrm{RhB}$ degradation was observed for the bismuth oxide sample $\left(k_{a}=3.75 \times 10^{-5} \mathrm{~s}^{-1}\right)$, while bismuth tungstate was slightly less efficient $\left(k_{a}=3.09 \times 10^{-5} \mathrm{~s}^{-}\right.$ $\left.{ }^{1}\right)$. In contrast to the bismuth-based coatings, the photocatalytic activity of titanium dioxide was very low, and the dye degradation rate was only marginally higher than that of photolysis alone. It is a known fact that photocatalytic efficiency of the samples strongly depends on such factors as optical properties and morphology. However, all three samples were characterised with similar values of the surface area (less than $1 \%$ variation), therefore, all studied samples had comparable areas of contact with the model pollutant and their photocatalytic properties could be compared directly.

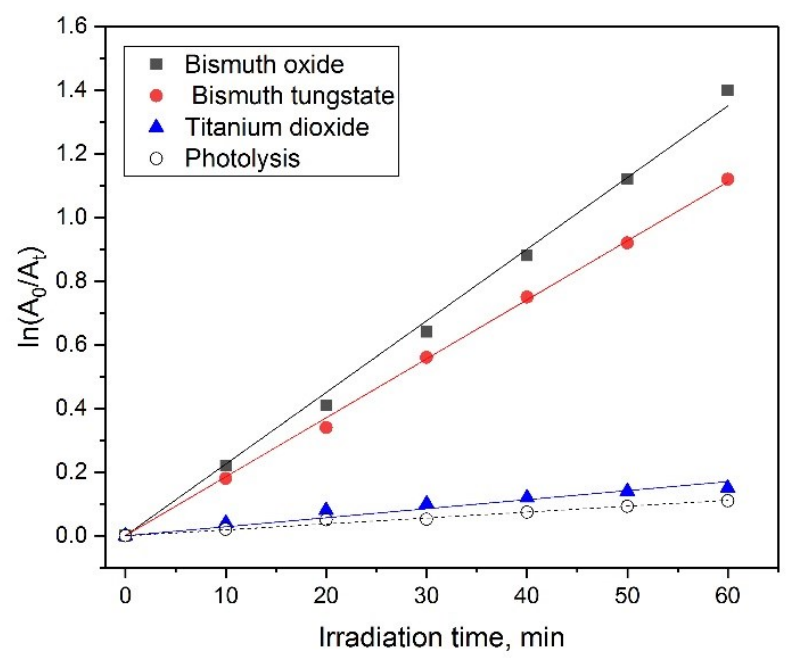

Figure 4. RhB degradation kinetics under visible light irradiation in contact with coatings deposited onto $2 \mathrm{~mm}$ glass beads annealed at $673 \mathrm{~K}$

\subsection{Photoinduced wettability measurements}




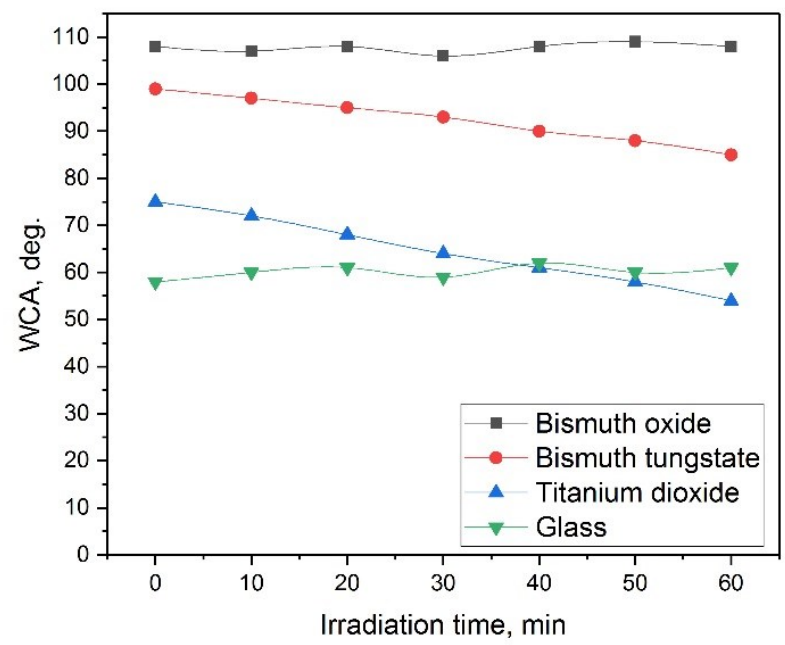

Figure 5. Time dependence of water contact angle under visible light irradiation of coatings deposited onto flat substrate and annealed at $673 \mathrm{~K}$

The photoinduced wettability of the films was studied by measuring the change of water contact angle on the surface of the flat glass substrates, while being irradiated with visible light (the same light source as in the RhB degradation experiments was used for the wettability tests). The same measurements were performed for an uncoated glass substrate. The changes in contact angle under light irradiation during 60 min experiments are shown in Figure 5. While all three studied coatings had comparable values of average surface roughness (slightly higher for the Bi-based films), the wettability values were distinctively different. Whereas the titanium dioxide film started at a lower angle and exhibited a gradual development of hydrophilic properties, both bismuth oxide and bismuth tungstate remained rather hydrophobic by the end of the 1-hour experiment, particularly the bismuth oxide coating. No significant changes in water contact angle value were observed for the uncoated glass.

\subsection{Antimicrobial and adhesion activity}

The initial assessment of antimicrobial activity was performed for $72 \mathrm{~h}$ under the visible light source; the results are presented in Figure 6 . It is evident that glass beads coated with bismuth oxide and bismuth tungstate were both able to reduce the number of viable $E$. coli cells in suspension to below the level of detection (BLD) within 72 hours, whilst under illumination (Figures $6 c$ and $6 d$ ), while the same beads kept in the dark exhibited no log decrease of cell numbers across the 72 hours.

Uncoated glass beads and glass beads coated with titanium dioxide (Figures $6 \mathrm{~b}$ and $6 \mathrm{e}$, respectively) both demonstrated a relatively smaller decrease in viable cells of approximately 1 to $2 \log \mathrm{CFU} / \mathrm{mL}$, compared to their dark counterpart. The experimental condition containing no beads had little change in CFU/mL across the 72 hours experiment (Figure 6a), in either the illuminated or dark conditions. This demonstrates that visible light-mediated photocatalysis using bismuth-based coatings was able to significantly $(\mathrm{P}<0.0001)$ reduce $E$. coli numbers from an initial large inoculum. 

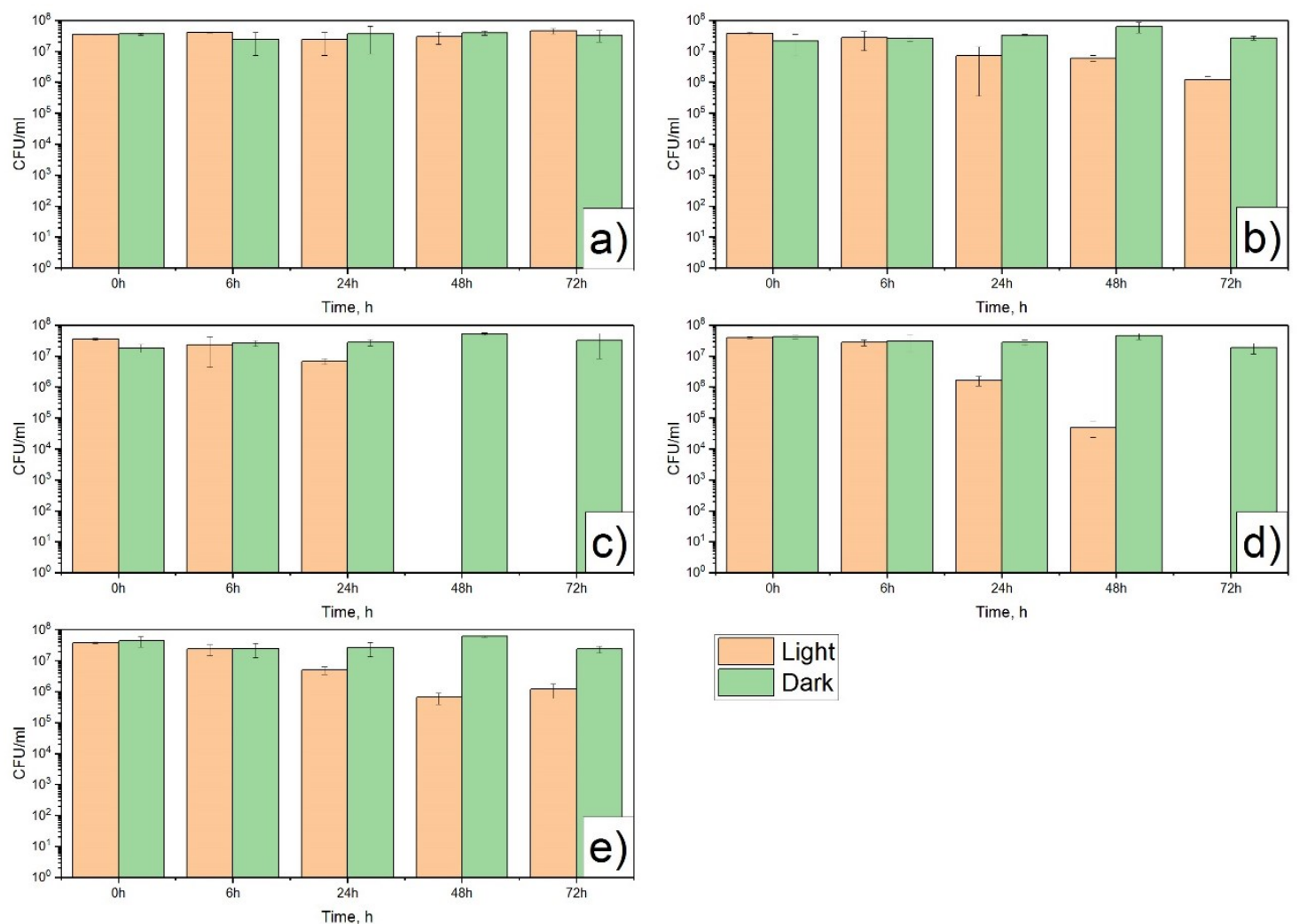

Light

Dark

Figure 6. Number of microbial cells (CFU mL-1) recovered from wells containing: a) no glass beads, b) glass beads with no coatings; c) glass beads coated with bismuth oxide; d) glass beads coated with bismuth tungstate; e) glass beads coated with titanium dioxide (after $72 \mathrm{~h}$ irradiation with the visible light)

Following the antimicrobial activity experiment described above, the adhesion experiments were performed to ensure that reduction in cell numbers described above was not solely due to differential cell adhesion to the beads. The results of the adhesion experiment are depicted in the Figure 7. As can be seen, cells were recovered from the titanium dioxide-coated glass beads only, whilst no cells were recovered from the glass beads coated with either bismuth oxide or bismuth tungstate. These data are in good agreement with the wettability measurements described earlier. WCA analysis demonstrates that bismuth oxide was the most hydrophobic coating of the array. Hydrophobicity of a surface has previously been shown to affect the ability of microorganisms to adhere to surfaces [45], with a higher hydrophobicity resulting in fewer adhered cells. 


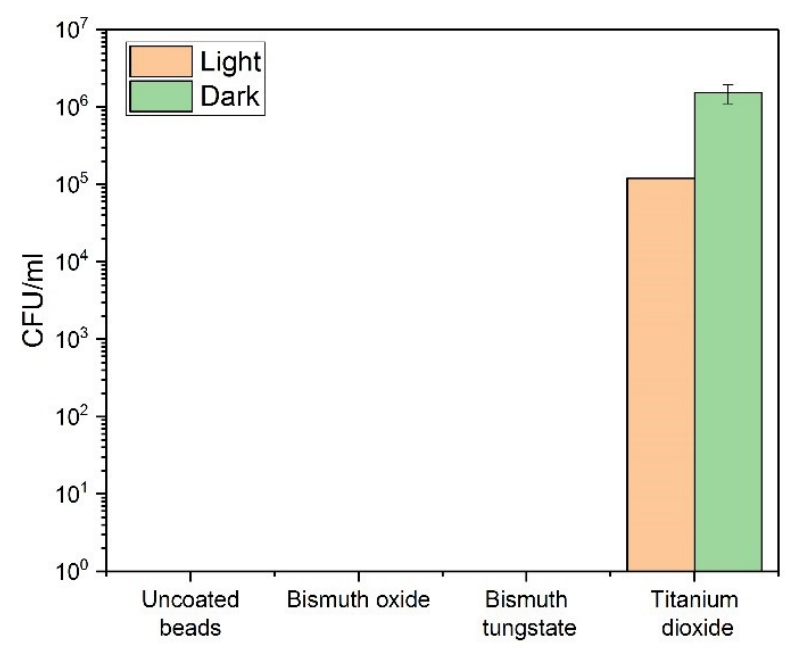

Figure 7. Number of microorganisms (CFU mL-1) recovered from pooled data $(n=10)$ following 72 hours of being submerged in $1 \mathrm{~mL}$ of E. coli suspension, rotating at $110 \mathrm{RPM}$ at room temperature

Further verification of above-mentioned suggestion that higher hydrophilicity promotes cell adhesion was obtained by investigating cell adhesion to the flat substrates coated with the same materials. The results of the adhesion assay of $E$. coli on flat surfaces coated with bismuth oxide, bismuth tungstate and titanium dioxide are shown in the Figure 8 . As can be seen, the average percentage coverage of cells on an uncoated glass substrate and titanium dioxide coatings were $2.52 \%$ and $2.77 \%$, respectively, and were not significantly different ( $p>0.05$ ), whilst average coverage values for bismuth oxide and bismuth tungstate-coated surfaces were considerably lower $-0.57 \%$ and $1.13 \%$, respectively. Clearly, the percentage coverage between the bismuth-based coatings, compared to uncoated glass and titanium dioxide-coated glass were significantly different $(p<0.0001)$. These results suggest that both bismuth oxide and bismuth tungstate coatings offer an additional antifouling property compared to the titanium dioxide films conventionally used in photocatalysis. This is advantageous, because if a photocatalytic coating were to be covered in adhered microorganisms more quickly than it was able to destroy the cells, light would be prevented from reaching the surface, rendering the photocatalytic properties of the coating redundant. 


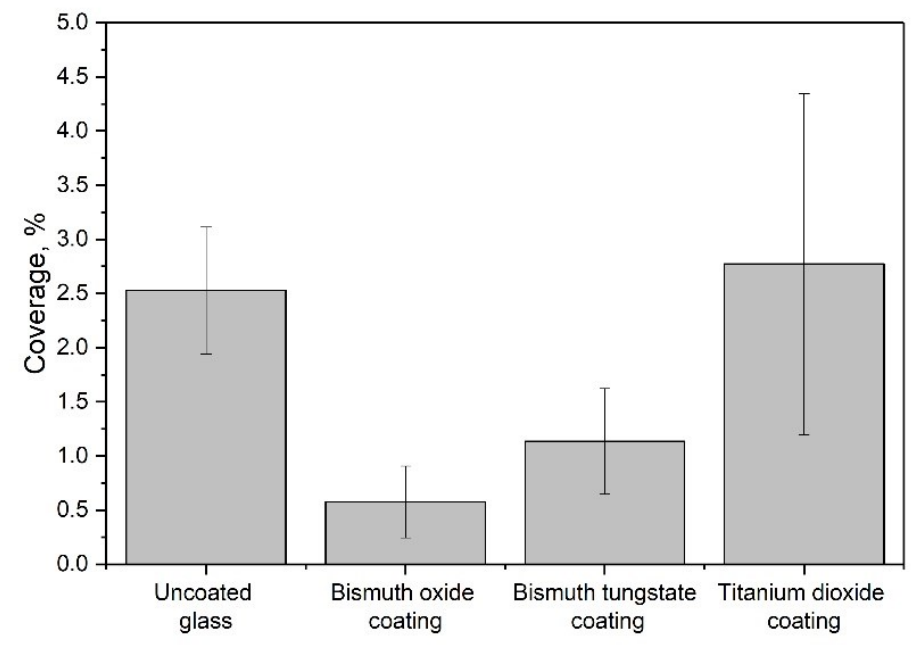

Figure 8. Percentage coverage of E. coli adhered to flat glass substrates with no coating, or coated with bismuth oxide, bismuth tungstate or titanium dioxide

Additionally, glass beads, both uncoated and coated with bismuth oxide (the most antimicrobiallyactive sample of the array) were tested for their ability to remove adhered cells from stainless steel in an agitated environment. According to the scanning laser confocal microscopy results presented in Figure 9, both sets of beads considerably reduced the number of cells remaining on the surface. As the beads were continuously moving across the surface of the stainless steel it is likely that the reduction of adhered cells is due to physical removal as the beads run across the surface of the steel. This action would result in freely floating cells. To this end, the distilled water that the beads and steel had been placed in was tested for the presence of microorganisms. E. coli was recovered from all wells (figure 10). The number of $\mathrm{CFU} / \mathrm{mL}$ recovered from the wells without any beads and from the wells containing uncoated glass beads were $8.5 \times 10^{7}$ and $7.48 \times 10^{6}$, respectively. The number of $\mathrm{CFU} / \mathrm{mL}$ recovered from the wells containing bismuth oxide coated beads was $4.3 \times 10^{3}$, a $99.9 \%$ (three-log) decrease, compared to the uncoated glass beads.
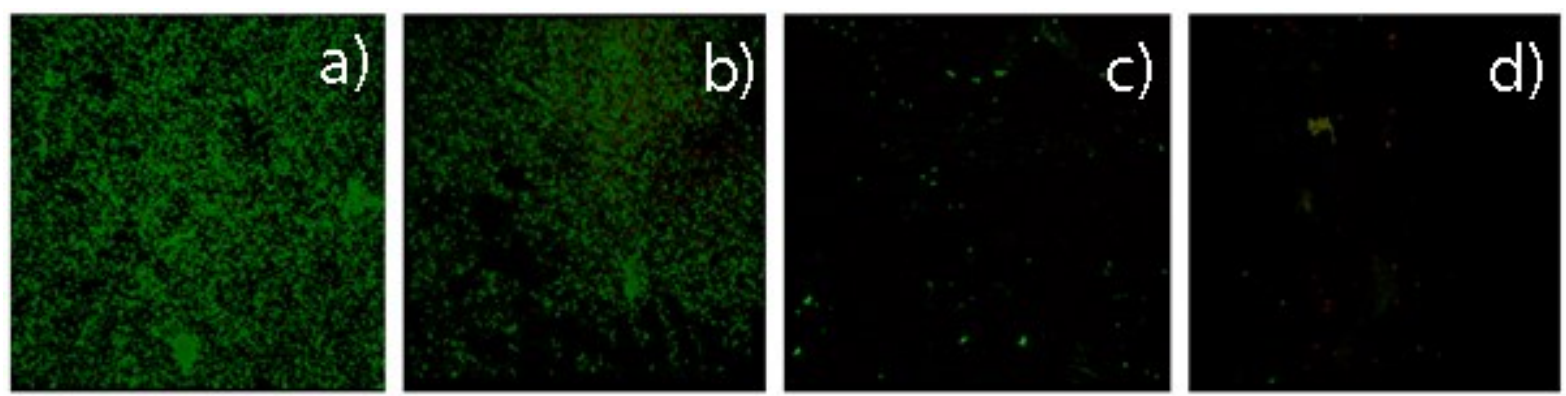

Figure 9. Scanning laser confocal microscopy images showing example of adhered $E$. coli coverage after: a) Oh; b) $72 \mathrm{~h}$ without glass beads; c) $72 \mathrm{~h}$ with the uncoated glass beads; $d$ ) $72 \mathrm{~h}$ with bismuth oxide-coated beads (Cells were stained with SYTO 9 dye to show live cells and propidium iodide to stain dead cells) 


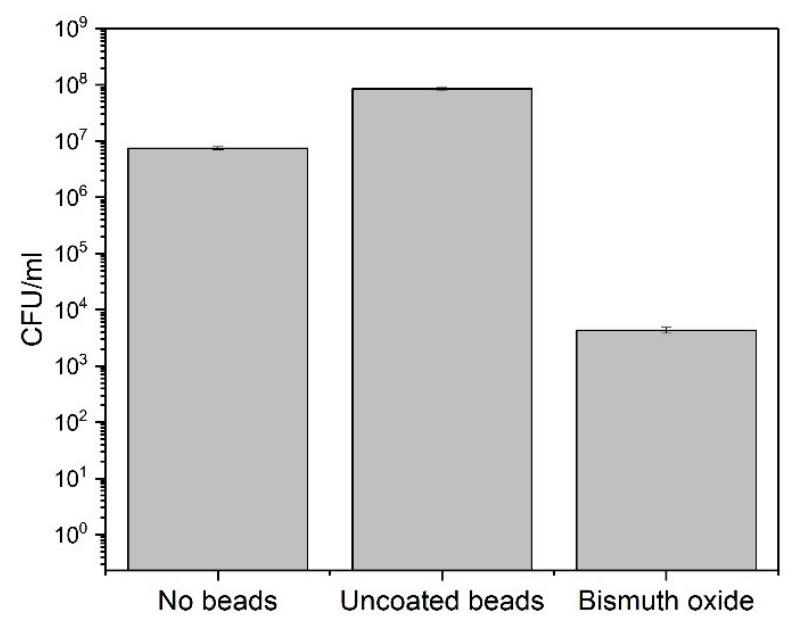

Figure 10. Number of colony forming units (living bacteria - E. coli) recovered after $72 \mathrm{~h}$ from each well originally containing a stainless steel coupon with adhered E. coli. Prior to the introduction of beads, the stainless-steel coupons had been

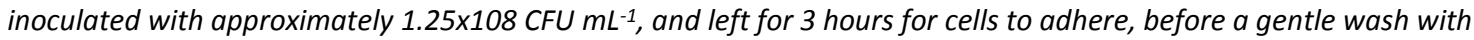
distilled water to remove non-adhered cells. Each well also contained either no beads, uncoated glass beads, or bismuth oxide-coated beads

\section{Discussion}

While the photocatalytic process is frequently reported as a promising and sustainable technique for the removal of contaminants and the inactivation of microbial pathogens, the industrial implementation of this process is still limited due to slower kinetics and low photoactivity under natural sunlight. A wide range of narrow band gap semiconducting materials have been proposed, synthesized and tested as potential alternatives to titanium dioxide. However, it is important to note that for the efficient application of the photocatalyst to "real-life" processes, such as water treatment, it is important to assess not only its ability to photodegrade various chemical contaminants, but also its ability to photo-inactivate pathogenic microorganisms. Nevertheless, while antimicrobial properties of titanium dioxide are relatively well studied, the visible lightactivated narrow band gap semiconducting materials are rarely reported for their ability to photoinactivate microorganisms.

The materials reported here include titanium dioxide (the most used photocatalytic material), bismuth tungstate (frequently mentioned as an efficient visible light photocatalyst) and bismuth oxide. While the photocatalytic bactericidal activity of titanium dioxide under UV light has been confirmed by a large number of publications, it is inefficient under purely visible light, due to the high band gap value. Indeed, titanium dioxide coatings produced in this work exhibited a band gap value of $3.21 \mathrm{eV}$, being in a good agreement with the typically reported band gap values of anatase [12]. On the contrary, both of types bismuth-based coatings were characterised with relatively low band gap values, though still being in good agreement with the values seen in the literature (band gap values of bismuth tungstate range from 2.5 to $2.8 \mathrm{eV}$, depending on the phase and stoichiometry $[23,31]$, while the band gap of bismuth oxide is frequently reported to be around 2.5 $\mathrm{eV}$ [36]). It is obvious that the photocatalytic tests results here were in direct correlation with the optical properties of the coatings studied, where the highest photocatalytic activity was observed for the sample with the narrowest band gap (bismuth oxide). Not surprisingly, titanium dioxide with a 
relatively wide band gap of $3.21 \mathrm{eV}$ could not be photoactivated using the chosen visible light source and, therefore, was not efficient in the photodegradation of the selected model pollutant, Rhodamine B dye.

It is a known fact that titanium dioxide exhibits the phenomenon of photoinduced hydrophilicity when irradiated with sub-band gap light. Though hydrophilicity is frequently mentioned in the context of discussing photocatalytic oxidation, these two phenomena have been shown to be independent $[46,47]$. Thus, the photoinduced hydrophilicity of titanium dioxide is reported to be a result of structural changes in $\mathrm{TiO}_{2}$ itself that lead to preferential adsorption of water [48]. Therefore, the photocatalytic oxidation reaction is not necessary accompanied with the development of photoinduced hydrophilicity, which is obviously the case with bismuth oxide (no reduction in WCA over a $1 \mathrm{~h}$ experiment). Hydrophilicity development on the surface of titanium dioxide was rather surprising, as the light source used emitted purely visible light below the energy required for photoactivation of the material with a band gap of $3.21 \mathrm{eV}$. However, it should be noted here, that despite all the efforts to minimise the impact of ambient light, during preparation for the WCA measurements, the coatings were unavoidably exposed to light that contains a small fraction of UV, which presumably accounts for the small reduction of WCA observed for the titanium dioxide sample. Also, due to the impurities, surface defects and dangling bonds some residual absorption develops in $\mathrm{TiO}_{2}$ leading to the decrease in the observed WCA.

The reactions taking place upon the irradiation of the photocatalytic materials with the sub-band gap light source are commonly described as follows: generation of the charge carriers (a), production of ROS (b), and oxidation / reduction processes (c):

a) Photocatalyst $+h v \rightarrow$ Photocatalyst $+e^{-}+h^{+}$

b) $e^{-}+\mathrm{O}_{2} \rightarrow \cdot \mathrm{O}_{2}^{-} / \cdot \mathrm{HO}_{2}$ $h^{+}+\mathrm{HO}_{2} \rightarrow \cdot \mathrm{HO}+\mathrm{H}^{+}$

c) $\cdot \mathrm{O}_{2}^{-} / \cdot \mathrm{HO}_{2}+$ pollutant $\rightarrow \mathrm{H}_{2} \mathrm{O}+\mathrm{CO}_{2}$

$\cdot \mathrm{HO}+$ pollutant $\rightarrow \mathrm{H}_{2} \mathrm{O}+\mathrm{CO}_{2}$

Though the exact mechanism of photocatalytic inactivation of microorganisms is still under debate, it is generally accepted that inhibition of the microbial growth that occurs in contact with the photocatalyst is due to cell membrane destruction by reactive oxygen species (ROS), produced via reactions (2) and (3), leading to the cell lysis and death [49-51]. Amongst the ROS, hydroxyl radicals are often mentioned as the main driving force of photocatalytic bactericidal effect [9].

No major difference in the pathway of the destruction mechanism has been reported for titanium dioxide and non- $\mathrm{TiO}_{2}$ based photocatalytic materials [35, 50, 52, 53]. Moreover, monitoring of the evolution of $\mathrm{K}^{+}$during bacterial inactivation (as indicative of the cells viability loss [50]) has been shown to follow the same trend for titanium dioxide and bismuth tungstate-based photocatalytic $E$. coli inactivation [33].

It is a frequently reported fact that the hydrophilicity / hydrophobicity of the surface may affect bacterial adhesion, where higher wettability enables better adhesion of the bacterial species to the surface [54]. Thus, as reported by Falde et al, the adhesion of bacteria can be limited by such factors as a hydrophobic surface or entrapped air [55]. Indeed, hydrophobic surfaces are often mentioned in the literature with respect to their ability to prevent bacterial adhesion, compared with more hydrophilic surfaces $[54,56]$, with use of superhydrophobic surfaces being widely accepted as one of 
the most promising strategies for reduction of bacterial adhesion [57]. On the contrary, titanium dioxide is widely known for its superhydrophilic properties when irradiated with UV light; the surfaces typically return to higher values of the water contact angle when the irradiation stops.

While photocatalytic materials (most frequently - titanium dioxide) find application in the water treatment sector, fouling of the photocatalyst over the cycle of use is a major issue $[5,58]$. The adhesion of microorganisms to the surface of the photocatalyst with subsequent biofilm formation is more likely to happen during periods of photocatalyst "inactivity" (e.g. night-time in solar-light irradiated reactors). In turn, once the biofilm develops to a certain thickness, it may completely block the light reaching the surface of the photocatalyst, and thus completely cease its activity [59]. From this perspective, the relatively hydrophobic bismuth oxide (and also, to a lesser extent, bismuth tungstate) provides an additional advantage of surface hydrophobicity, even when irradiated with the sub-band gap light, and therefore, prevent bacterial adhesion to the surface, as compared to the titanium dioxide coatings, tested under identical conditions. Though long-term trials are required to study this phenomenon in more detail, the above-mentioned property may be indicative of the anti-fouling effect of the bismuth-based photocatalytic materials studied, that, along with the lower band gap value and higher photocatalytic efficiency, makes them attractive candidates for visible-light mediated water treatment processes.

Though the initial findings of the present work are very encouraging, further information on photocatalytic antimicrobial efficiency of bismuth oxide against different microorganisms should be advantageous for overall understanding of the material properties. Moreover, the physico-chemical properties of the microorganisms themselves may affect their adhesion to the substrates $[56,60]$. The follow-up work on in-depth assessment of antimicrobial properties of bismuth oxide is currently in progress, including its efficiently against various common water-borne pathogens, and study of the antifouling properties of the material, as well as stability tests.

Therefore, we believe that the findings of the present paper are of particular importance, as the antimicrobial properties of bismuth oxide coatings have not been reported previously, with the observed efficiency in the $E$. coli inactivation under visible light source being superior to both titanium dioxide and bismuth tungstate. Moreover, the hydrophobic nature of bismuth oxide coatings and lower adhesion of bacterial species to its surface (without any additional surface modification) is a highly desirable quality for application as a light-activated antimicrobial material, as in this case it may not only photo-inactivate the bacterial species, but also prevent fouling of the surface.

\section{Conclusion}

This paper discusses the photocatalytic efficiencies of three different types of coatings, deposited onto $2 \mathrm{~mm}$ glass beads, namely bismuth oxide, bismuth tungstate and titanium dioxide, under visible light irradiation. The coatings were deposited via reactive magnetron sputtering of metallic targets in an argon / oxygen atmosphere, followed by post-deposition annealing in air at $673 \mathrm{~K}$ for $30 \mathrm{~min}$. The photocatalytic properties of the coated beads were initially tested using a Rhodamine B dye degradation test, and then verified with a series of microbiological assays. It was found that bismuth oxide-coated beads significantly outperform other samples of the array in both dye degradation, and microorganism inactivation experiments. 
Owing to the low band gap value $(2.4 \mathrm{eV})$ and the ability to utilize visible light efficiently, bismuth oxide coated beads reduced the number of viable $E$. coli cells in suspension to below the limit of detection in the first $48 \mathrm{~h}$ of irradiation. Additionally, the bismuth oxide coatings provide an additional advantage of hydrophobic surfaces that remain unchanged even under sub-band gap irradiation, though being able to reduce the ability of microorganisms to adhere to the surface, compared to uncoated glass, bismuth tungstate or titanium dioxide. This phenomenon is likely to afford bismuth oxide coatings additional antifouling properties compared to conventional titanium dioxide-based photocatalytic coatings. We believe that these findings, along with the follow-up studies on bismuth oxide antimicrobial efficiency against common water-borne pathogens, are likely to be of interest to those involved in visible or solar light-irradiated water treatment systems, where effective disinfection of the treated media is as important as degradation of the pollutants.

\section{Acknowledgement}

This Special Issue is dedicated to honour the retirement of Dr John Kiwi at the Swiss Federal Institute of Technology (Lausanne), a key figure in the topic of photocatalytic materials for the degradation of contaminants of environmental concern.

\section{$\underline{\text { References }}$}

[1] T. Mano, S. Nishimoto, Y. Kameshima, M. Miyake, Water treatment efficacy of various metal oxide semiconductors for photocatalytic ozonation under UV and visible light irradiation, Chem. Eng. J., 264 (2015) 221-229.

[2] G.D. O'Mullan, M. Elias Dueker, A.R. Juhl, Challenges to Managing Microbial Fecal Pollution in Coastal Environments: Extra-Enteric Ecology and Microbial Exchange Among Water, Sediment, and Air, Curr. Pollut. Rep., 3 (2017) 1-16.

[3] M. Vortmann, S. Balsari, S.R. Holman, P.G. Greenough, Water, Sanitation, and Hygiene at the World's Largest Mass Gathering, Curr. Infect. Dis. Rep., 17 (2015) 5.

[4] H.K. Fujishima A., Kikuchi S., Photosensitized electrolytic oxidation on semiconducting n-type TiO2 electrode, Kogyo Kagaku Zasshi, 72 (1969) 108-113.

[5] M.N. Chong, B. Jin, C.W.K. Chow, C. Saint, Recent developments in photocatalytic water treatment technology: A review, Water Res., 44 (2010) 2997-3027.

[6] P.V. Laxma Reddy, B. Kavitha, P.A. Kumar Reddy, K.-H. Kim, TiO2-based photocatalytic disinfection of microbes in aqueous media: A review, Environ. Res., 154 (2017) 296-303.

[7] BSI, BS ISO 27447:2009 Fine ceramics (advanced ceramics, advanced technical ceramics). Test method for antibacterial activity of semiconducting photocatalytic materials, BSI, London, 2009.

[8] S.C. Edberg, E.W. Rice, R.J. Karlin, M.J. Allen, Escherichia coli: the best biological drinking water indicator for public health protection, J. Appl. Microbiol., 88 (2000) 106S-116S.

[9] A. Markowska-Szczupak, K. Ulfig, A.W. Morawski, The application of titanium dioxide for deactivation of bioparticulates: An overview, Catal. Today, 169 (2011) 249-257.

[10] S. Rehman, R. Ullah, A.M. Butt, N.D. Gohar, Strategies of making TiO2 and ZnO visible light active, J. Haz. Mater., 170 (2009) 560-569.

[11] M. Ratova, P.J. Kelly, G.T. West, I. Iordanova, Enhanced properties of magnetron sputtered photocatalytic coatings via transition metal doping, Surf. Coat. Technol., 228, Supplement 1 (2013) S544-S549.

[12] M. Ratova, R. Klaysri, P. Praserthdam, P.J. Kelly, Visible light active photocatalytic C-doped titanium dioxide films deposited via reactive pulsed DC magnetron co-sputtering: Properties and photocatalytic activity, Vacuum, 149 (2018) 214-224.

[13] M.V. Dozzi, E. Selli, Doping TiO2 with p-block elements: Effects on photocatalytic activity, J. Photochem. Photobiol. C, 14 (2013) 13-28. 
[14] M. Hernández-Alonso, Metal Doping of Semiconductors for Improving Photoactivity, in: J.M. Coronado, F. Fresno, M.D. Hernández-Alonso, R. Portela (Eds.) Design of Advanced Photocatalytic Materials for Energy and Environmental Applications, Springer London 2013, pp. 269-286.

[15] M. Ratova, P.J. Kelly, G.T. West, L. Tosheva, M. Edge, Reactive magnetron sputtering deposition of bismuth tungstate onto titania nanoparticles for enhancing visible light photocatalytic activity, Appl. Surf. Sci., 392 (2017) 590-597.

[16] M. Ratova, P. Kelly, G. West, L. Tosheva, A Novel Technique for the Deposition of Bismuth Tungstate onto Titania Nanoparticulates for Enhancing the Visible Light Photocatalytic Activity, Coatings, 6 (2016) 29.

[17] S. Dong, J. Feng, M. Fan, Y. Pi, L. Hu, X. Han, M. Liu, J. Sun, J. Sun, Recent developments in heterogeneous photocatalytic water treatment using visible light-responsive photocatalysts: a review, RSC Adv., 5 (2015) 14610-14630.

[18] M. Ratova, R. Marcelino, P. de Souza, C. Amorim, P. Kelly, Reactive Magnetron Sputter Deposition of Bismuth Tungstate Coatings for Water Treatment Applications under Natural Sunlight, Catalysts, 7 (2017) 283.

[19] S. Kunduz, G.S. Pozan Soylu, Highly active BiVO4 nanoparticles: The enhanced photocatalytic properties under natural sunlight for removal of phenol from wastewater, Sep. Purif. Technol., 141 (2015) 221-228.

[20] Y. Shen, M. Huang, Y. Huang, J. Lin, J. Wu, The synthesis of bismuth vanadate powders and their photocatalytic properties under visible light irradiation, J. Alloys Compd., 496 (2010) 287-292.

[21] V. Sivakumar, R. Suresh, K. Giribabu, V. Narayanan, BiVO4 nanoparticles: Preparation, characterization and photocatalytic activity, Cogent Chemistry, 1 (2015).

[22] J. Hou, S. Jiao, H. Zhu, R.V. Kumar, Facile synthesis and visible-light photocatalytic activity of bismuth titanate nanorods, J. Nanopart. Res., 13 (2011) 5557-5564.

[23] M. Ratova, G.T. West, P.J. Kelly, Photocatalytic visible-light active bismuth tungstate coatings deposited by reactive magnetron sputtering, Vacuum, 115 (2015) 66-69.

[24] M. Ratova, P. Kelly, G. West, X. Xia, Y. Gao, Deposition of Visible Light Active Photocatalytic Bismuth Molybdate Thin Films by Reactive Magnetron Sputtering, Materials, 9 (2016) 67.

[25] Y. Shimodaira, H. Kato, H. Kobayashi, A. Kudo, Photophysical Properties and Photocatalytic Activities of Bismuth Molybdates under Visible Light Irradiation, J. Phys. Chem. B, 110 (2006) 1779017797.

[26] M.D. Hernandez-Alonso, F. Fresno, S. Suarez, J.M. Coronado, Development of alternative photocatalysts to TiO2: Challenges and opportunities, Energy Environ. Sci., 2 (2009) 1231-1257. [27] L. Zhang, Y. Zhu, A review of controllable synthesis and enhancement of performances of bismuth tungstate visible-light-driven photocatalysts, Catal. Sci. Technol., 2 (2012) 694-706.

[28] X. Lin, Z. Liu, X. Guo, C. Liu, H. Zhai, Q. Wang, L. Chang, Controllable synthesis and photocatalytic activity of spherical, flower-like and nanofibrous bismuth tungstates, Mater. Sci. Eng. B, 188 (2014) 35-42.

[29] F. Amano, K. Nogami, B. Ohtani, Enhanced photocatalytic activity of bismuth-tungsten mixed oxides for oxidative decomposition of acetaldehyde under visible light irradiation, Catal. Comm., 20 (2012) 12-16.

[30] G. Li, D. Zhang, J.C. Yu, M.K.H. Leung, An Efficient Bismuth Tungstate Visible-Light-Driven Photocatalyst for Breaking Down Nitric Oxide, Environ. Sci. Technol., 44 (2010) 4276-4281. [31] X. Chu, G. Shan, C. Chang, Y. Fu, L. Yue, L. Zhu, Effective degradation of tetracycline by mesoporous Bi2WO6 under visible light irradiation, Front. Environ. Sci. Eng., (2014) 1-8.

[32] X. Lu, Y. Peng, Z. Han, Heterogeneous photocatalytic treatment of wastewater in ultraviolet light irradiation-photocatalyst Bi2WO6 microsphere with high repeatability, Front. Optoelectron., 5 (2012) 439-444.

[33] S. Helali, M.I. Polo-López, P. Fernández-Ibáñez, B. Ohtani, F. Amano, S. Malato, C. Guillard, Solar photocatalysis: A green technology for E. coli contaminated water disinfection. Effect of 
concentration and different types of suspended catalyst, J. Photochem. Photobiol. A, 276 (2014) 3140.

[34] Y.-S. Xu, Z.-J. Zhang, W.-D. Zhang, Facile preparation of heterostructured Bi2O3/Bi2MoO6 hollow microspheres with enhanced visible-light-driven photocatalytic and antimicrobial activity, Mater. Res. Bull., 48 (2013) 1420-1427.

[35] R. Sharma, Uma, S. Singh, A. Verma, M. Khanuja, Visible light induced bactericidal and photocatalytic activity of hydrothermally synthesized BiVO4 nano-octahedrals, J. Photochem. Photobiol. B, 162 (2016) 266-272.

[36] B. Sirota, J. Reyes-Cuellar, P. Kohli, L. Wang, M.E. McCarroll, S.M. Aouadi, Bismuth oxide photocatalytic nanostructures produced by magnetron sputtering deposition, Thin Solid Films, 520 (2012) 6118-6123.

[37] J.C. Medina, M. Bizarro, P. Silva-Bermudez, M. Giorcelli, A. Tagliaferro, S.E. Rodil, Photocatalytic discoloration of methyl orange dye by $\delta$-Bi2O3 thin films, Thin Solid Films, 612 (2016) 72-81.

[38] P.J. Kelly, R.D. Arnell, Magnetron sputtering: a review of recent developments and applications, Vacuum, 56 (2000) 159-172.

[39] P.J. Kelly, G.T. West, M. Ratova, L. Fisher, S. Ostovarpour, J. Verran, Structural Formation and Photocatalytic Activity of Magnetron Sputtered Titania and Doped-Titania Coatings, Molecules, 19 (2014) 16327-16348.

[40] J. Tauc, R. Grigorovici, A. Vancu, Optical Properties and Electronic Structure of Amorphous Germanium, Physica Status Solidi (b), 15 (1966) 627-637.

[41] J. Schindelin, I. Arganda-Carreras, E. Frise, V. Kaynig, M. Longair, T. Pietzsch, S. Preibisch, C. Rueden, S. Saalfeld, B. Schmid, J.-Y. Tinevez, D.J. White, V. Hartenstein, K. Eliceiri, P. Tomancak, A. Cardona, Fiji: an open-source platform for biological-image analysis, Nat. Methods, 9 (2012) 676. [42] M.P. Seah, C.A. Clifford, F.M. Green, I.S. Gilmore, An accurate semi-empirical equation for sputtering yields I: for argon ions, Surf. Interface Anal., 37 (2005) 444-458.

[43] B. Bharti, S. Kumar, H.-N. Lee, R. Kumar, Formation of oxygen vacancies and $\mathrm{Ti}(3+)$ state in $\mathrm{TiO}_{2}$ thin film and enhanced optical properties by air plasma treatment, Sci. Rep., 6 (2016) 32355.

[44] S. Zeng, R. Tang, S. Duan, L. Li, C. Liu, X. Gu, S. Wang, D. Sun, Kinetically controlled synthesis of bismuth tungstate with different structures by a NH4F assisted hydrothermal method and surfacedependent photocatalytic properties, J. Colloid. Interface Sci., 432 (2014) 236-245.

[45] J. Verran, K. Whitehead, Factors Affecting Microbial Adhesion to Stainless Steel and Other Materials Used in Medical Devices, Int. J. Artif. Organs, 28 (2005) 1138-1145.

[46] R. Wang, K. Hashimoto, A. Fujishima, M. Chikuni, E. Kojima, A. Kitamura, M. Shimohigoshi, T. Watanabe, Photogeneration of Highly Amphiphilic TiO ${ }_{2}$ Surfaces, Adv. Mater., 10 (1998) 135-138. [47] M. Miyauchi, A. Nakajima, T. Watanabe, K. Hashimoto, Photocatalysis and Photoinduced Hydrophilicity of Various Metal Oxide Thin Films, Chem. Mater., 14 (2002) 2812-2816.

[48] M. Miyauchi, A. Nakajima, A. Fujishima, K. Hashimoto, T. Watanabe, Photoinduced Surface Reactions on TiO2 and SrTiO3 Films: Photocatalytic Oxidation and Photoinduced Hydrophilicity, Chem. Mater., 12 (2000) 3-5.

[49] T. Matsunaga, R. Tomoda, T. Nakajima, H. Wake, Photoelectrochemical sterilization of microbial cells by semiconductor powders, FEMS Microbiol. Lett., 29 (1985) 211-214.

[50] W. Wang, Y. Yu, T. An, G. Li, H.Y. Yip, J.C. Yu, P.K. Wong, Visible-Light-Driven Photocatalytic Inactivation of E. coli K-12 by Bismuth Vanadate Nanotubes: Bactericidal Performance and Mechanism, Environ. Sci. Technol., 46 (2012) 4599-4606.

[51] H.A. Foster, I.B. Ditta, S. Varghese, A. Steele, Photocatalytic disinfection using titanium dioxide: spectrum and mechanism of antimicrobial activity, Appl. Microbiol. Biotechnol., 90 (2011) 18471868.

[52] P. Ganguly, C. Byrne, A. Breen, S.C. Pillai, Antimicrobial activity of photocatalysts: Fundamentals, mechanisms, kinetics and recent advances, Appl. Catal. B, 225 (2018) 51-75. 
[53] P.S.M. Dunlop, C.P. Sheeran, J.A. Byrne, M.A.S. McMahon, M.A. Boyle, K.G. McGuigan, Inactivation of clinically relevant pathogens by photocatalytic coatings, J. Photochem. Photobiol. A, 216 (2010) 303-310.

[54] Y. Yuan, M.P. Hays, P.R. Hardwidge, J. Kim, Surface characteristics influencing bacterial adhesion to polymeric substrates, RSC Adv., 7 (2017) 14254-14261.

[55] E.J. Falde, S.T. Yohe, Y.L. Colson, M.W. Grinstaff, Superhydrophobic materials for biomedical applications, Biomaterials, 104 (2016) 87-103.

[56] G.M. Bruinsma, H.C. van der Mei, H.J. Busscher, Bacterial adhesion to surface hydrophilic and hydrophobic contact lenses, Biomaterials, 22 (2001) 3217-3224.

[57] X.X. Zhang, L. Wang, E. Levanen, Superhydrophobic surfaces for the reduction of bacterial adhesion, Rsc Adv., 3 (2013) 12003-12020.

[58] W. Zhang, L. Ding, J. Luo, M.Y. Jaffrin, B. Tang, Membrane fouling in photocatalytic membrane reactors (PMRs) for water and wastewater treatment: A critical review, Chem. Eng. J., 302 (2016) 446-458.

[59] A. Katz, A. McDonagh, L. Tijing, H.K. Shon, Fouling and Inactivation of Titanium Dioxide-Based Photocatalytic Systems, Crit. Rev. Environ. Sci. Technol., 45 (2015) 1880-1915.

[60] K.A. Whitehead, J. Verran, The Effect of Substratum Properties on the Survival of Attached Microorganisms on Inert Surfaces, in: H.-C. Flemming, P.S. Murthy, R. Venkatesan, K. Cooksey (Eds.) Marine and Industrial Biofouling, Springer Berlin Heidelberg, Berlin, Heidelberg, 2009, pp. 13-33. 